\title{
Non-Prescription Medicine Mobile Healthcare Application: Smartphone-Based Software Design and Development Review
}

\author{
https://doi.org/10.3991/ijim.v11i5.7123 \\ Orawit Thinnukool ${ }^{(凶)}$, Pattaraporn Khuwuthyakorn, Purida Wientong \\ Chiang Mai University, Chiang Mai, Thailand \\ orawit.tecmu.ac.th \\ Thammarat Panityakul \\ Prince of Songkla University, Songkhla, Thailand
}

\begin{abstract}
The challenge of this research is to answer the question of what the real need of users regarding the development of a smartphone-based software for healthcare application. This study aimed to develop the nonprescription drugs mobile health application (NMMHA) to support users in the initial medication. The application has been released to evaluate tested its usability and satisfaction. To ensure the NMMHA is going to perform well, a survey has been conducted to collect data about the opinions of two groups of responders (pharmacists and general people). An attitude test and statistical analysis have also been accomplished for both groups to determine the differentiation between the two groups. The impressive results indicate that the group of general peoples tend to use the application more than the group of pharmacists, whereas the overall attitude test results of the two groups are not different.
\end{abstract}

Keywords - mobile healthcare application, non-prescription drugs, satisfaction, performance, reliability.

\section{Introduction}

The modern world is quickly changing human behaviors every day. Recent technological advances influence daily activities and create new challenges and opportunities for different areas including healthcare. Information technology in the healthcare industry has been utilizing electronic devices to perform a range of tasks which has improved the outcome for patients. Recently, patients are encouraged to engage in their own healthcare using mobile applications [1-5].

A healthcare applications are defined as associated tools for treating and monitoring patients. These tools facilitate communication, patient self-management and monitoring patient symptoms, remote monitoring the health or the location of patients and providing healthcare information and suggestions. There are many benefits of smartphone which play an important role to track or manage patients' health [6-7]. 
Nowadays, the number of smartphones in use is growing rapidly, and corresponding to the number of healthcare application, the use of smartphones is getting more attention steadily. Approximately, at the present day about two billions of smartphones are in use. Moreover, it is predicted that, in 2018, the number of smartphone users worldwide will increase to six billions [8-10]. Android claim the largest market of the top smartphone operating systems in use with an $82.8 \%$ share in 2015 [11].

When examining the proportion of smartphone users and the number of mobile software applications, the results indicate that $19 \%$ of smartphone users installed at least one healthcare application on their devices according to Duggan and Rainie and $52 \%$ of users used the application to search for healthcare information [12].

Furthermore, Lee suggests that there is a rapid growth of mobile software applications associated with healthcare. It has been discovered recently that $46 \%$ of healthcare professionals say that they want to introduce mobile software applications to their practice in the next five years [13]. Regarding the results, the need of healthcare mobile software applications is more than 100,000 needs as mentioned in Aditi [14] and more than 1.7 billion people downloaded healthcare applications [15].

Pharmacy mobile application is a type of healthcare applications which greatly benefits patients by providing information about various pharmaceutical products. Nowadays, when a patient needs primary healthcare, smartphone is the first tool that is used to search for relevant information and a suitable treatment before going to the hospital or pharmacy [16]. As we have seen, pharmacy mobile applications are widely used to search medicine information, because of convenience, ease of access and reduced healthcare costs [17-19]. Although users can easily download a mobile application to their devices, but not all of them can perfectly suit their needs. For example, some functions may not serve users or fit to users' behavior such as when the users always forget medication information, or when the patients want to contact the pharmacists or doctors, etc.

One of the challenges during the development of healthcare mobile applications is to consider what the real users' needs are. There are many aspects which are important and must be considered by the developer during the development process, such as, feasibility, reliability, stability, security and accuracy [20]. Moreover, attitude and confidence are two factors that help to identify whether or not users accept the application. While, the graphical user interface (GUI) and system performance can increase user satisfaction regarding the development techniques and enhance the number of participants on healthcare application [21].

There is one more thing to remember when a user download an application onto a device is that the developer has an opportunity only once to get the user's attention and encourage the user to use the application again and again. If the application does not provide stunning useful functions to satisfy the user's needs, it is strongly believed that it would be the last time for the user to use the particular application. As a result, it is very important to analyze and clarify what user needs would be and choose wisely what functions the application would have when developing an application. We also considered about the favorite functions or mobile applications that users rely 
on when they want to search for healthcare information or healthcare services and locations.

Recently, a mobile software application for providing pharmacy information called "Non-Prescription Medicine Mobile Health Application (NMMHA)" was designed and developed [22]. The first version of the software contains two main functions: searching for medicine information and setting time to take medicine. The user satisfaction result shows the proven evidence of the software acceptance, however some functions were recommended by users during the software testing process. In this second version of the NMMHA, we focused on function adding and improving the mobile software application corresponding to user feedback in Thinnukool.

In this paper, the study aimed to: (1) to develop the second version of the NMMHA healthcare mobile application for non-prescription based on Android operating system; (2) to evaluate user feedback regarding GUI, system performance, confidence and attitude on mobile healthcare application. Descriptive statistics were used to analyze the results. The expected outcomes of this study is to provide an appropriate tool which is able to support the real need in personal healthcare for people who have or never have experience in pharmacy or self-healthcare. There are two groups of samples were used for testing users' differentiation. Consequently, to examine the assumption of the study, hypothesis was set as following. $\left(\mathrm{H}_{0}\right.$ : percentage of pharmacist - percentage of general people $=0, \mathrm{H}_{1}$ : percentage of pharmacist - percentage of general people $<=0$ )

(i) User acceptant levels of two sample groups in using the mobile health application as a tool in the initial medication are not different.

(ii) Levels of agreement of two sample groups about the graphic user interface of NMMHA are not different.

(iii) Levels of agreement of two sample groups about NMMHA application usage are not different.

(iv) Levels of agreement of two sample groups about the reliance in NMMHA are not different.

(v) Overall levels of agreement of two sample groups for the NMMHA application are not different.

\section{$2 \quad$ Material and Methods}

\subsection{Medicine Contents}

In Thailand, the Ministry of Public Health is the organization which defines the list of non-prescription medicines which are safe and effective for use by the general public legally without seeking treatment by a health professional. In this study, the non-prescription medicine information was used in the NMMHA application. Fifty two types of non-prescription medicines are grouped in the NMMHA database (Bureau of Drug Control) [22]. List of medicine groups of non-prescription medicines is shown in Table 1. 
Table 1. List of medicine groups of non-prescription medicines.

\begin{tabular}{|l|l|}
\hline \multicolumn{1}{|c|}{ Medicine Group } & \multicolumn{1}{c|}{ Medicine Group } \\
\hline Analgesic/Antipyretic & Laxatives \\
Antihistamine & Parasiticides \\
Cough medicine & Muscle relaxants \\
Aromatic inhaler & Ophthalmic medicine \\
Anti-motion sickness & Dermal/Topical medicine \\
Oral and Throat medicines & Wound healing medicines \\
Antacids & Antiseptics \\
Antidiarrheal medicine & Vitamins \\
\hline
\end{tabular}

\subsection{Non-Prescription Medicine Mobile Health Application (NMMHA)}

The NMMHA has been improved from the first version [23] and its responsiveness has been added to address user feedback. The App Inventor [24] and SDLC (adaptive waterfall) [25] were used for development. Both versions have been prepared under Android operation system platform, because the majority of mobile device users is based on Android operating system. The user satisfaction for both user interface design [26] and user acceptance were applied [27-30]. Functions from the first version NMMHA have been improved corresponding to user suggestion which is indicated in Table 2.

Table 2. List of user suggestion of the first version NMMHA and improvement issue.

\begin{tabular}{|l|l|l|}
\hline \multicolumn{1}{|c|}{ Problem } & \multicolumn{1}{|c|}{ Users Suggestion } & \multicolumn{1}{c|}{ Improvement Issue } \\
\hline $\begin{array}{l}\text { The application does not } \\
\text { have location services }\end{array}$ & $\begin{array}{l}\text { They want application to have } \\
\text { location services to find pharmacy } \\
\text { locations }\end{array}$ & $\begin{array}{l}\text { Develop the pharmacy loca- } \\
\text { tion service }\end{array}$ \\
\hline The GUI proportion & $\begin{array}{l}\text { Some front size is too small, some } \\
\text { pictures and buttons are not locat- } \\
\text { ed on appropriate side }\end{array}$ & $\begin{array}{l}\text { Redesign and resize pictures } \\
\text { and buttons }\end{array}$ \\
\hline System speed & $\begin{array}{l}\text { Application speed is too slow and } \\
\text { sometimes does not immediately } \\
\text { respond }\end{array}$ & $\begin{array}{l}\text { Fixing the speed and reduce } \\
\text { size of the application }\end{array}$ \\
\hline $\begin{array}{l}\text { Does not have function to } \\
\text { remind about medicine } \\
\text { information }\end{array}$ & $\begin{array}{l}\text { They want to application to have } \\
\text { a function to remind them when } \\
\text { they forgot to take medicine }\end{array}$ & $\begin{array}{l}\text { Develop a reminder for medi- } \\
\text { cine intake by recording a } \\
\text { sound of suggestion or typing } \\
\text { words into the application. }\end{array}$ \\
\hline $\begin{array}{l}\text { In emergency case, they } \\
\text { want to have a function to } \\
\text { ask for help }\end{array}$ & $\begin{array}{l}\text { The function can ask somebody to } \\
\text { help patient }\end{array}$ & $\begin{array}{l}\text { Develop a function for alerting } \\
\text { somebody specified by the } \\
\text { user }\end{array}$ \\
\hline
\end{tabular}

After improving according to the real user needs, the NMMHA version 2 in the Beta version has been released on the Play Store of Google. After testing on the completed functions, graphic user interface has been evaluated again to ensure that all components on the interface are correct. GUI check list was use to evaluate. 
In the NMMHA version 2 provides the useful functions to use non-prescription medicines. The NMMHA screen shots are shown in Figure 1 and Figure 2. In Figure 1 , the mobile software application contains a main page (A) which is categorized into six main functions. When a user clicks on the F1 function, the application will show operational tasks of the F1 function indicated on the next panel (B).

The F1 function is illustrated in operational sub-functions which search for groups of medicines (separated by each symptom condition). Whereas, the F2 function icon on $(A)$ is a function of reminding about user in tolerance information which is shown in Figure 2(D). Other functions of the NMMHA version 2 application are described in Table 3.

After completing the final Beta version, the NMMHA has been uploaded on to the Google Play for groups of responders in this research to download.

\subsection{Demographic characteristics of participants}

There are two sample groups were selected. The first group consists of pharmacists and the second one consists of general people selected by random sampling technique. We chose the samples of pharmacists from Chiang Mai University drug store and general group from the drug store around the campus. The difference between the two groups involves the knowledge associated with medicine (people know how to use non-prescription medicine when sick). Group one (the pharmacist group) has prior knowledge of non-prescription drug usage, but group two (students and general people, etc.) do not have. This sample groups are for evaluation purposes including the evaluation of satisfaction, performance and reliability which was identified through testing the NMMHA. Table 4 illustrates sample size for each group.

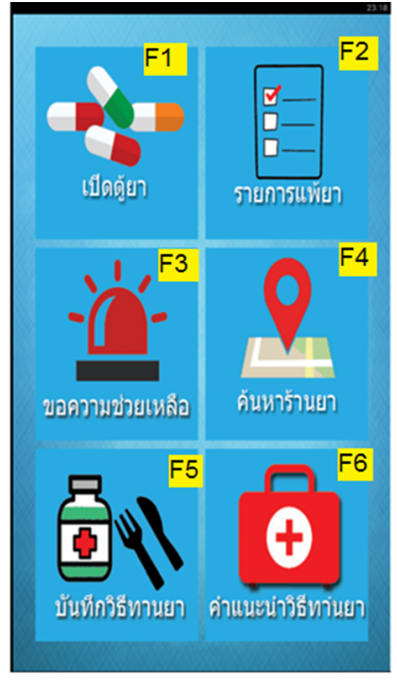

A

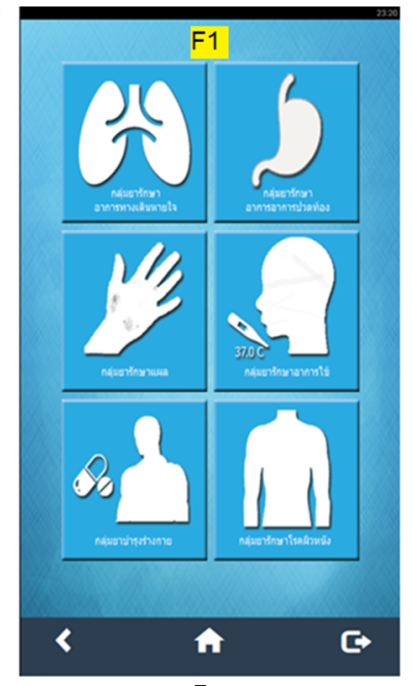

B

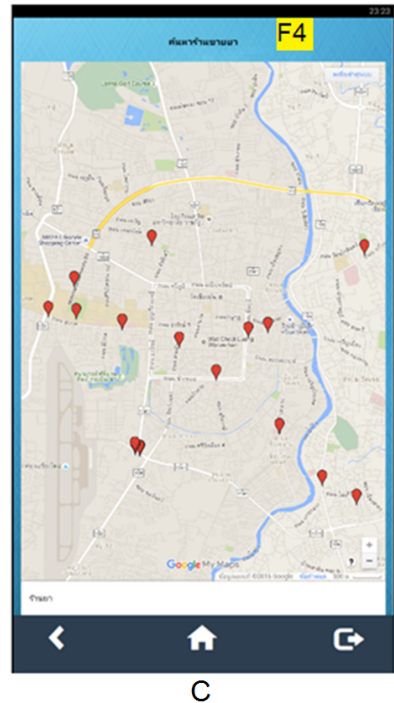

C

Fig. 1. Sample of the graphical user interface (A) shows on main menu and illustrates operational task in each function (B-C). 

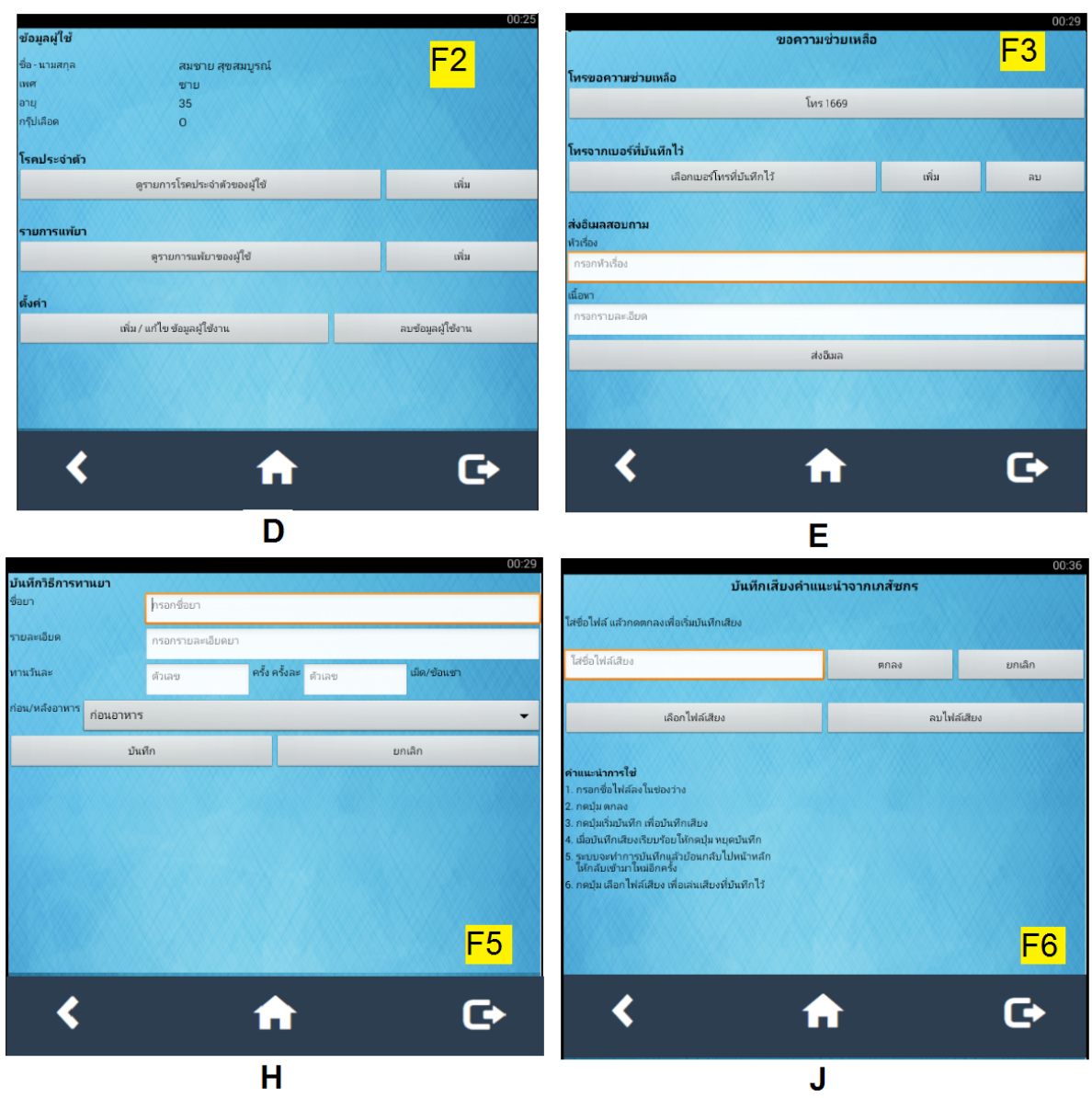

Fig. 2. The graphical user interface shows operation function in each main menu (D-J) which corresponding to main menu in Figure 1 (A).

Table 3. Functional requirements of the NMMHA version 2

\begin{tabular}{|l|l|l|}
\hline \multicolumn{1}{|c|}{ Main Function } & \multicolumn{1}{|c|}{ Sub-function } & \multicolumn{1}{c|}{ How to use } \\
\hline 1.Drug store (F1) & $\begin{array}{l}\text { Indicate drug list by } \\
\text { symptom (B) }\end{array}$ & $\begin{array}{l}\text { Click each drug list by symptom to see medicine } \\
\text { information }\end{array}$ \\
\hline $\begin{array}{l}\text { 2.Remind about medicine } \\
\text { information (F2) }\end{array}$ & Record an information of intolerance \\
\hline 3.Emergency (F3) & $\begin{array}{l}\text { Call or send an e-mail to } \\
\text { people that recorded }\end{array}$ & $\begin{array}{l}\text { Record contact information such as phone number, e- } \\
\text { mail, Click it when patient have emergency case. }\end{array}$ \\
\hline $\begin{array}{l}\text { 4.Pharmacy location } \\
\text { service (F4) }\end{array}$ & - & $\begin{array}{l}\text { User can find by click to drug store that close to user } \\
\text { current position }\end{array}$ \\
\hline $\begin{array}{l}\text { 5.Remind how to take } \\
\text { drug (F5) }\end{array}$ & - & $\begin{array}{l}\text { Typing drug information such as drug name, dose to } \\
\text { take, timing, then user selects each list after record. }\end{array}$ \\
\hline $\begin{array}{l}\text { 6.Recording a sound of } \\
\text { suggestion (F6) }\end{array}$ & - & $\begin{array}{l}\text { Record suggestion of pharmacists and user can re- } \\
\text { trieve that information after record. }\end{array}$ \\
\hline
\end{tabular}


Table 4. Sampling of the experiment

\begin{tabular}{|l|c|c|c|}
\hline \multirow{2}{*}{ Group } & \multicolumn{2}{c|}{ Samples } & \multirow{2}{*}{ Total } \\
\cline { 2 - 3 } & Male & Female & \\
\hline Pharmacist & 11 & 21 & 32 \\
\hline General & 15 & 21 & 36 \\
\hline Total & 26 & 42 & 68 \\
\hline
\end{tabular}

Table 5 shows the result that indicates the demographic information of responders (refer to the section one of the questionnaire). An experiment was designed and conducted to study the potential of the NMMHA application. We administered before surveying to cover a wide range of responders including pharmacists and general people. The survey has been planned for collecting the information regarding pharmacists and general people's perceived competency in using mobile devices and their behavior for using similarly available mobile healthcare applications.

Table 5. Demographic samples

\begin{tabular}{|l|c|c|}
\hline \multicolumn{1}{|c|}{ Group } & \multicolumn{2}{|c|}{ Sample } \\
\cline { 2 - 3 } Age & Pharmacist n (\%) & General $\boldsymbol{n}$ (\%) \\
20-30 & $\mathrm{n}=32$ & $\mathrm{n}=36$ \\
$31-40$ & 50.00 & 30.56 \\
40up & 23.33 & 22.22 \\
Occupation & 26.57 & 47.22 \\
Community pharmacist & 28.79 & - \\
Hospital pharmacist & 3.03 & - \\
Faculty member & 10.61 & - \\
Public health pharmacist & 3.03 & - \\
Other & - & 54.55 \\
Residency & & 27.27 \\
within Chiang Mai Municipality areas & 22.73 & 27.27 \\
Outlying districts & 22.74 & - \\
Education & & - \\
bachelor of pharmacy, 5 y program & 18.18 & - \\
Pharm D & 18.18 & 24.24 \\
higher than bachelor's degree & 9.09 & 21.21 \\
bachelor's degree & - & Yes=58.33 \\
Lower bachelor's degree & - & 30.33 \\
Mobile device usage & Yes=56.67 & 38.89 \\
iOS & 53.33 & 58.33 \\
Android & 33.33 & 43.33 \\
Ever known the Mobile Health Application & & \\
\hline
\end{tabular}

\subsection{Interview}

The section one of the questionnaire is about personal information of responders, whereas section two indicates the level of agreement of the survey statements which are about using the mobile health application as a tool in the initial medication. The interviews have been conducted along with the questionnaire to collect the data from responders during 23-26 May, 2016. 
The last section of the questionnaire has been conducted by letting responders try the NMMHA on the provided devices (10-15 minutes). Then, they were questioned to indicate a level of agreement of the following survey statements. This section of the questionnaire stimulated response opinions of each criterion on the screen, for example, buttons, color, size of the font, background and foreground. It also elicited user opinions associated with user confidence. After finishing the interviews, all of the responders have been suggested to download the NMMHA application from Google Play via a direct gateway.

\subsection{Questionnaire}

The questionnaire used for evaluation in this study determined users' satisfaction, attitude, and confidence into 5 levels by following the Likert scale; 5-strongly agree, 4-agree, 3-neutral, 2-disagree and 1-strongly disagree. In this experiment, it was assumed that rating 5, 4 and 3 are agree opinion, whereas 2 and 1 are disagree opinion. Table 6 demonstrates questions of the questionnaire used in the study, excluding section one: personal information of responders. The result of the questionnaire represents satisfaction, performance, and reliability of responders including pharmacist and general people on the use of the NMMHA application.

Table 6. List of questions in the questionnaire used for interview in responders, excluding section one: personal information.

\begin{tabular}{|c|c|}
\hline No. & Questions \\
\hline \multicolumn{2}{|r|}{$\begin{array}{c}\text { Indicate level of agreement of the survey statements about using mobile health application as a tool in } \\
\text { the initial medication }\end{array}$} \\
\hline Q2:1 & $\begin{array}{l}\text { Mobile health applications can be an instrument in providing information on the initial medi- } \\
\text { cation and resulting an effective treatment. }\end{array}$ \\
\hline Q2:2 & $\begin{array}{l}\text { Mobile health applications can provide accurate information on the healthcare as same as } \\
\text { professional advice from pharmacists and doctors. }\end{array}$ \\
\hline Q2:3 & Using of mobile health applications can make personal healthcare better. \\
\hline Q2:4 & $\begin{array}{l}\text { Using of mobile health applications can change behaviors and encourage users to care more } \\
\text { about their personal health. }\end{array}$ \\
\hline Q2:5 & Using of mobile health applications will not be seriously harmful to the users' health. \\
\hline Q2:6 & $\begin{array}{l}\text { Using of mobile health applications can reduce the bill for medication when the users get } \\
\text { sick. }\end{array}$ \\
\hline Q2:7 & Using of mobile health applications can facilitate the users in the initial medication. \\
\hline \multicolumn{2}{|r|}{ Level of agreement about the Graphic User Interface (GUI) } \\
\hline Q3:1 & Buttons on the screen are easy to use. \\
\hline Q3:2 & The screen is clearly distinctive between foreground and background. \\
\hline Q3:3 & Screen colors are appropriate. \\
\hline Q3:4 & Each of the menu images represents understandable functionality. \\
\hline Q3:5 & The number of menu is appropriate to use. \\
\hline Q3:6 & Menu list is easy to use. \\
\hline Q3:7 & Text sizes are appropriate. \\
\hline Q3:8 & Contrast of the display is beautifully balanced. \\
\hline
\end{tabular}




\begin{tabular}{|c|c|}
\hline Q3:9 & Users like the overall user interface design, the screen. \\
\hline \multicolumn{2}{|r|}{ Level of agreement about the application usage (Experiment) } \\
\hline Q31:1 & The application is easy to use and intuitive. \\
\hline Q31:2 & The application provides useful information on the use of non-prescription drugs. \\
\hline Q31:3 & Allergic Record function is useful for the treatment and can protect users' drug allergies. \\
\hline Q31:4 & Emergency Call is a useful function to inform about any irregularities in taking medicines. \\
\hline Q31:5 & $\begin{array}{l}\text { Pharmacy Search Function can help users to find community pharmacies more quickly and } \\
\text { easily. }\end{array}$ \\
\hline Q31:6 & Medicine Record Function (print) allows users to easily record how to take the medicine. \\
\hline Q31:7 & Medicine Record Function (sound) is a useful function to take medicines correctly. \\
\hline Q31:8 & When receiving information from the application, users can take the medicine on their own. \\
\hline Q31:9 & The application can help users in self-medication using non-prescription drugs. \\
\hline Q31:10 & The application quickly and stably runs on mobile device platform. \\
\hline \multicolumn{2}{|r|}{ Level of agreement about the reliance on the use of application functionality. } \\
\hline Q32:1 & You have confidence in the applications about the instructions for the initial medication. \\
\hline Q32:2 & You believe that the application provides information about drugs with accuracy. \\
\hline Q32:3 & $\begin{array}{l}\text { The Non-prescription Drugs function can provide accurate information of medicines as well } \\
\text { as the advice from professional like pharmacists. }\end{array}$ \\
\hline Q32:4 & $\begin{array}{l}\text { The information provided on the application helps users to understand how to use medicines } \\
\text { and are able to use that information for immediate treatment. }\end{array}$ \\
\hline Q32:5 & You believe that the information given by the application will do no harm to the users. \\
\hline Q32:6 & You accept the application and would recommend it to friends. \\
\hline Q32:7 & $\begin{array}{l}\text { If you are in an area where there is no pharmacist to advice on drugs, you would use the } \\
\text { application to search and buy drugs on your own. }\end{array}$ \\
\hline Q32:8 & Using of the application can reduce the cost of healthcare. \\
\hline Q32:9 & The application Medicine function will facilitate users in the initial medications. \\
\hline Q32:10 & You will download and suggest other people to use the application. \\
\hline
\end{tabular}

\section{$3 \quad$ Results}

The first section shows the hypothesis of this experiment and the corresponding result is shown in Figure 3. The first bar chart shows proportion of percentage of the pharmacist group agree: percentage of the pharmacist group disagree whereas next bar chart shows proportion of the percentage of the general group agree: percentage of the general group disagree, where the footnote in each panel explains the result of testing by using $p$-value.

The first hypothesis is rejected, $\mathrm{H}_{0}$ means the levels of user acceptance of two groups about using mobile health application as a tool in the initial medication are different ( $p$-value $=0.0056$ ) by the proportion agreement of the pharmacist group is $90 \%$ whereas disagreed is $10 \%$. While, the proportion of agreement in the general people group is $95 \%$ and disagree is $5 \%$, respectively.

The second hypothesis in the next two of bar chart is rejected, $\mathrm{H}_{0}$ means the levels of agreement of two groups about the GUI of the NMMHA application are different ( $p$-value $=0.0001)$ by the proportion of the agreement in the pharmacist group which is 
$90 \%$ and disagree is $10 \%$, whereas the proportion of agreement in the general group is $99 \%$ and disagree is $1 \%$.

The third hypothesis in the next two of bar chart is rejected, $\mathrm{H}_{0}$ means the levels of agreement of two groups about the NMMHA application usage are different $(\mathrm{p}=0.0206)$, when consider the proportion of agreement of the pharmacist group is $95 \%$, and the reject is $5 \%$. Strongly result by the proportion of agreement in general group is $99 \%$ whereas just a few percentages only $1 \%$ is disagree.

Fourth hypothesis is rejected, $\mathrm{H}_{0}$ means the levels of agreement of two groups about the reliance of NMMHA are different ( $p$-value $=0.001$ ). The proportion of the agreement in the pharmacist group is $90 \%$, whereas the general group is $99 \%$.

Finally, the last hypothesis in last of two bar chart in Figure 3 has been tested of the overall levels of agreement of two groups for the NMMHA application are not different $(p$-value $=0.0001)$. The result shows that hypothesis is rejected, H1 means the two groups are agreed. As we have seen the proportion of agreement, the result indicates the levels of the agreement in the pharmacist group is $90 \%$, and disagree is $10 \%$. Whereas, the overall proportion of agreement level in general group is $99 \%$, where only $1 \%$ rejected the NMMHA application.

The hypothesis testing result states that the difference of agreement levels between the pharmacist group and the general people group is portly significant. It shows pvalue of all parts are less than the significant level of 0.05 . Furthermore, the levels of agreement of the general people group tend to overcome the level of agreement of the pharmacist group. Thus, the consecutive testing is necessary. For instance, the higher level of agreement of the general people group is close to $95 \%$ in part (i), whereas the pharmacist group is $90 \%$ agreement level. The result of consecutive tests in part (ii), (iii), (iv) and (v) shows the same manner. The result leads to the conclusion of the agreement level of the general people group is higher than the level of the pharmacists group.

Moreover, the testing result illustrates the outcome of the NMMHA. The information from Google is one point for consideration to track whether participants are still interested in the application or not. The result from developer console in Google Play is able to indicate the information of software downloads. Figure 4 shows some statistics and the number of downloads from May 23, 2016 (start date of the survey) and number have increased in the next following days unit May 27, 2016. However, as seen on Figure 4, the bar chart demonstrates the number of visitors (no download) as well. The number of those who have visited the NMMHA application on the Google Play without downloading was 84 visitors, whereas the number of people who have visited and installed was 34 . 
Paper-Non-Prescription Medicine Mobile Healthcare Application: Smartphone-Based Software Design...

\begin{tabular}{|c|c|c|c|}
\hline Agreer & ent & Disagreement & \\
\hline H0:P.Phr.A : P.Pher.DisA & $p$-value $=0.6528$ & $90 \%$ & $10 \%$ \\
\hline Ho:P.Gen.A: P.Gen.DisA & $p$-value $=0.2546$ & $95 \%$ & $5 \%$ \\
\hline \multicolumn{4}{|l|}{ hypothesis (i) $p$-value $=0.0056$} \\
\hline H0:P.Phr.A:P.Pher.DisA & $p$-value $=0.1631$ & $90 \%$ & $10 \%$ \\
\hline H0:P.Gen.A : P.Gen.DisA & $p$-value $=0.2460$ & $99 \%$ & \\
\hline \multicolumn{4}{|l|}{ hypothesis (ii) $p$-value $=0.0001$} \\
\hline H0:P.Phr.A : P.Pher.DisA & $p$-value $=0.7913$ & $95 \%$ & $5 \%$ \\
\hline H0:P.Gen.A: P.Gen.DisA & $p$-value $=0.0443$ & $99 \%$ & \\
\hline \multicolumn{4}{|l|}{ hypothesis (iii) p-value $=0.0206$} \\
\hline H0:P.Phr.A : P.Pher.DisA & p-value $=0.4697$ & $99 \%$ & \\
\hline H0:P.Gen.A: P.Gen.DisA & $p$-value $=0.6153$ & $99 \%$ & \\
\hline \multicolumn{4}{|l|}{ hypothesis (iv) p-value $=0.0000$} \\
\hline H0:P.Phr.A : P.Pher.DisA & $p$-value $=0.0491$ & $90 \%$ & $10 \%$ \\
\hline Ho:P.Gen.A : P.Gen.DisA & $p$-value $=0.1297$ & $99 \%$ & \\
\hline hypothesis (v) p-value $=0.00 \mathrm{C}$ & & & \\
\hline
\end{tabular}

** $\mathrm{H}_{0}$ :P.Phr.A:P.Pher.DisA = proportion of percentage of the pharmacist group agree: percentage of the pharmacist group disagree

$* * \mathrm{H}_{0}:$ P.Gen.A:P.Gen.DisA = proportion of percentage of the general group agree: percentage of the general group disagree

Fig. 3. Bar chart show p-value and percentage proportion of agreement and disagree of testing in each group.

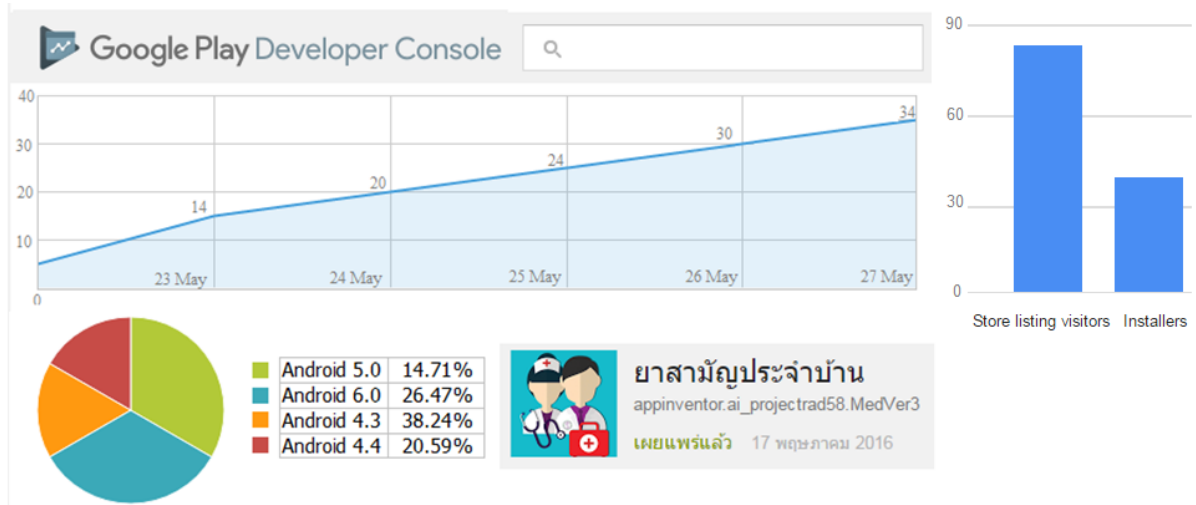

Fig. 4. Screen shot of the developer console account on Google Play which can indicates the download information from May 23-27, 2016 during the survey interviewing. The pie chart shows a proportion of downloads separated by Android version. 


\section{Discussion}

This study aimed to develop the non-prescription drugs mobile health application for support real-user need in the initial medication. The application has been developed based on Android operation system which is one of the most popular operating systems used by the majority [11]. The researcher expected users will be able to sympathize when the application is released on the Play Store.

The version 2 of the NMMHA application has six main functions including drug store, medicine information reminder, emergency, pharmacy locations and services, solution record for taking medicines and sound record of the professional suggestion. The mobile application has been evaluated by two groups of responders, pharmacists and general people, using a questionnaire together with interviewing. The questionnaire focused on three main points including agreement of using mobile health application as a tool in the initial medication, agreement about the application usage, agreement about the reliance on the use of application functionality, respectively.

The result points out that each hypothesis shows the different opinion of two sample groups. Let's consider the proportion of agreement of two groups, it is a clear confirmation of the difference as shown in Figure 3. The value of the general group is quit higher than pharmacists group in the testing hypothesis i-iv. The last hypothesis agreed then the overall of testing confirm the agreement of two groups were not different. The result shows that two group are agree in using mobile health application as a tool in the initial medication. As we have seen, the result of testing and agreement proportion of two groups were quite high. The level of agreement about the GUI result claims that they appreciated the GUI, whereas the application functionality can meet their needs as well.

However, when we focused on the encouragement of people to pay attention to their healthcare, the NMMHA application can be used as a tool of healthcare equipment. There were many smartphones with Android versions have visited the mobile software application on the Google Play page and downloaded. This shows how exciting of users in using or observing the proposed application. Another proven evident occurred by the interview section which each responder was suggested to download the NMMHA application. A report from the Developer Console account on the Google Play shows the Android version which are claimed that Android version 4.3 and 6.0 (Figure 4.) are widely used, whereas the result suggested the developer monitor regarding technical development when each version affects to speed and system performance.

While within next five years, as a study of Aditi P. [14], the paper claims that the number of the healthcare application will be more than 100,000 applications. This is an excellent opportunity for developers to prepare the development plan to produce useful applications to serve the market. Although, Android is still a popular operating system on mobile devices [11], a real need functionality would be placed as the first priority to consider more than a convenience and ease of access [17][19].

In terms of the benefits gained from using healthcare applications, many researchers claimed that mobile software applications can be used as a useful tool for monitoring and may be reducing a cost on healthcare as well [6-7][18]. Corresponding to the 
NMMHA application, it indicates the useful functions for instant, the function to record an information of intolerance, the function to remind users when they forget the information of their intolerance list. This function provides the answer to the real need of users when some responders always forget their intolerance list. The intolerance list can be recorded as systematic recording which is better than taking a photograph by a camera on a mobile device.

Moreover, many function such as the function for finding drug stores, the function to remind how to take drug or to remind about medicine information or recording a sound of suggestion are to support users for assistive medication which have been confirmed by the result in our experiment. Therefore, the NMMHA application can be claimed as a tool for medication which is corresponding to the mPharmacy [16].

Although, this study shows a good result of the second development of the NMMHA. But, the challenges during the development of the healthcare applications have to be the consideration of the real users' needs [26-30]. When the expectations such as reliability, stability, security and accuracy are also important points to be concerned in developing useful healthcare applications. Whereas, the study of the NMMHA application provides useful information to confirm that the application can be used as shown in the testing result (Figure 3 and Figure 4). The NMMHA application can be a useful tool in term of using in medication regarding to this experiment study.

On the other hand in term of opinion and attitude, the report of Mohamed et al. [3] has found an attitudes of pharmaceutical students and general publish on healthcare application, the result shows that the groups of sample did not rely to use the healthcare application because of education and knowledge of users are different.

Our study, the education levels of responders are not affect to their opinion and attitude. As shown in the demographic section, the information shows the general group have a similar proportion between responders who are educated in bachelor degree level and lower. Thus, education and knowledge might be not correlated to the use of the healthcare application. But, reason may be the understating of the benefits of the mobile system or the trend of technology in different countries as well.

\subsection{Limitations}

A couple limitations of this experiment are discussed in this section. Firstly, for this version of the NMMHA, the interviews and data collection were applied to a specific areas. So, the number of samples and the size of target areas of the further study need to be increased. Furthermore, for the long-term and larger scale efficiency study, technical security and research ethics will become issues.

In addition, study boundaries of the NMMHA application version 2 in term of technical system are follows;

(i) The speed for display GUI of Android version lower than 5.0 needs to be improved.

(ii) The resolution and sensitivity have to be fixed when display on screen less than 5.5 inches. 
(iii) Function for finding drug store locations should cover all the places while using the application and the connectivity need to be fixed.

(ix) The insensitivity when touching on screen is not immediately reaction. It needs to be improved.

\section{Conclusion}

The non-prescription drugs mobile health application (NMMHA) supports real users' needs in the initial medication. The version 2 of the NMMHA has been developed based on Android operation system.

Regarding to the result, the two sample groups, pharmacists and general people, have positive attitude and satisfactions to monitor their healthcare by agreement on the healthcare application. The result leads to the conclusion of the agreement level of the general people group is higher than the level of the pharmacists group by statistical significant at .001 .

Based on the NMMHA, the objective of this study was the useful development of the second version of the NMMHA application, but many functions and some focused points of GUI still need to be improved before releasing the version of 2.1 at the Google Play in an update version.

\section{Acknowledgment}

This research was funded by the College of Arts, Media and Technology, Chiang Mai University. Cooperative research and the development of the non-prescription drugs mobile health application is cooperation between the Chiang Mai University drugstore, Faculty of Pharmacy and the Embedded System and Mobile Application Laboratory, the College of Arts, Media and Technology, Chiang Mai University. Most of all, the correspondent author would like to thank Prof. Donald McNeil from the Macquarie University who educate the knowledge in research.

\section{$7 \quad$ References}

[1] Emine, S., and Marco, S. (2009). Mobile health access for diabetics in rural Areas of Turkey - results of a survey. Lecture Notes of the Institute for Computer Sciences, Social Informatics and Telecommunications Engineering, 27:13-20

[2] Li, J., Wu, X., and Chen, H. (2011). Research on mobile digital system based on internet of thing. Lecture Note in Electronically Engineering. 9:495-502. https://doi.org/10.1007/ 978-3-642-21747-0 62

[3] Mohamed, E.T., ClinPharm, M., Shazia, Q.J., and Mohamad, E.R. (2015). The use of medical and drug information software program for personal digital assistant among pharmacy student in a Malaysian pharmacy school. Current in Pharmacy Teaching and Learning. 7:484-491. https://doi.org/10.1016/j.cpt1.2015.04.015 
[4] Liliana, E., Pablo, Q., Luis, B.G., Lida, S., and Pedro-Pabblo, A. (2016). Open drugstores mobile app. New Advances in Information Systems and Technologies. 444:797-806. https://doi.org/10.1007/978-3-319-31232-3 75

[5] Shivani, G., Plinio, M., Gary, F.L., Catherine, Y., Emily, S., and Joseph, A. (2016). The systematic design of a behavioral mobile health application for the self-management of type 2 diabetes. Canadian Journal of Diabetes. 40:95-104. https://doi.org/10.1016/j.jcjd.2 015.06 .007

[6] Emine, S., and Marco, S. (2009). Mobile health access for diabetics in rural areas of Turkey-results of a survey. Lecture Notes of the Institute for Computer Sciences, Social Informatics and Telecommunications Engineering. 27:13-20.

[7] Mohammad Mosa, A.S., Yoo, I., and Sheet, L. (2012). A Systematic review of healthcare applications for smartphone. BMC Medical Informatics and Decision Making. 12(67):131.

[8] Gertner. (2015). Smartphone users. ; June 2, 2016. Available at: http://www.gartner.com/newsroom/id/2996817.

[9] Statista. (2015). Number of mobile phone users worldwide from 2012 to 2018 (in billions); May 31, 2015. Available at: http://www.statista.com/statistics/274774/for ecast-of-mobilephone-users-worldwide.

[10] Statista. (2015). Number of smartphone users worldwide from 2012 to 2018 (in billions); May 31, 2015. Available at: http://www.statista.com/statistics/330695/ number-of-smartphone-users-worldwide.

[11] IDC. (2015). Smartphone OS Market Share, 2015 Q2. ; May 30, 2016. Available at: http://www.idc.com/prodserv/smartphone-os-market-share.jsp.

[12] Duggan, M., and Rainie, L. (2012). Cell phone activities 2012: additional demographic analysis. Pew Research Internet Project. November 25, 2012. Available at: http://www.pewinternet.org/2012/11/25/additional-demographic-analysis-2.

[13] Lee, V. (2014). Mobile devices and apps for healthcare professionals: uses and benefits. Pharmacy and Therapeutics Journal. 39(5):356-364.

[14] Aditi, P. (2015). Survey: 46 percent of clinicians plan to use health apps in practices by 2020; May 5, 2016. Available at: http://mobihealthnews.com/

[15] Bruno, M.C., Joel, J.P.C., Isabel de la Torre, D., and Miguel, L.C. (2015). Mobile-health: A review of current state in 2015. Journal of Biomedical Informatics. 56:265 272. https://doi.org/10.1016/j.jbi.2015.06.003

[16] Charalmpos, D., Ilias, M., Panagiotis, T., Flora, M., and George, V. (2010). mPharmacy: A System enabling prescription and personal assistive medication management on mobile devices. Wireless Mobile Communication and Healthcare. 55:153-159.

[17] Ankur, A., Borko F., and Mamata, Y. (2013). Mobile medical and healthcare applications. Handbook of Medical and Healthcare Technologies. Springer New York Heidelberg Dordrecht London. 3-15.

[18] Pringle, J.L., Boyer, A., Conklin, M.H., McCullough, J.W., and Aldridge, A. (2014). The Pennsylvania Project: pharmacist intervention improved medication adherence and reduced healthcare costs. Health Affairs. 33(8):1444-1452. https://doi.org/10.1377/hlthaff. 2013.1398

[19] Tarek, M.E., Shazia, Q.J., and Ramadan, M.E. (2015). The use of medical and drug information software programs for personal digital assistants among pharmacy students in a Malaysian pharmacy school. Currents in Pharmacy Teaching and Learning. 7:484-491. https://doi.org/10.1016/j.cpt1.2015.04.015 
[20] Baig, M.M., Ghalarm, H.G., and Connolly, M.J. (2015). Mobile healthcare application: system design review, critical issues and challenges. Australasian Physical and Engineering Science in Medicine. 38:23-28. https://doi.org/10.1007/s13246-014-0315-4

[21] Devos, P., Min Jou, A., Waele G.D., and Petrovic, M. (2015). Design for personalized mobile health applications for enhanced older people participation. Technology Applied to Geriatric Medicine. 6:593-597. https://doi.org/10.1016/j.eurger.2015.10.004

[22] Bureau of drug control. Non-Prescription Medicine. June 20. (2015). Available at: http://drug.fda.moph.go.th/zone drug/dru003.asp.

[23] Thinnukool, O. (2017). Preliminary Design for development for non-prescription medicine mobile health application. Advanced Science Letters. In press.

[24] David, W., Hal, A., Ellen, S., and Liz, L. (2014). App Inventor. O’Reilly Media, Inc, 1005 Gravenstein Hightway North, Sebastopol, CA.

[25] James, M. (1991). Rapid Application Development. Maxwell Macmillan International Editions. New York, 10022.

[26] Thinnukool, O., and Kongchouy, N. (2017). The User's Satisfaction of Graphic User Interface in Designing for Health Care Mobile Application. Journal of Telecommunication, Electronic and Computer Engineering. 9(1-5):11-15.

[27] Caburnay, C.A., Graff, K., Harris, J. K., McQueen, A., Smith, M., Fairchild, M., and Kreuter, M. K. (2015). Evaluating Diabetes Mobile Applications for Health Literate Designs and Functionality. Preventing Chronic Disease. 12(61):1-13.

[28] Baysari, M. T., and Westbrook, J.I. (2015). Mobile Application for Patient-centered Care Coordination: A Review of Human Factors Method Applied to their Design, Development, and Evaluation. IMIA Yearbook of Medical Informatics. 10:47-54. https://doi.org/10.15265/IY-2015-011

[29] Norman, DA. (2002). The Design of Everyday Things, vol. xxi. 1st Basic paperback ed. New York: Basic Books, 257.

[30] Elizabeth, M., Jennifer, L.B., Kristine, L.O., Renee, M.R., Diana, D., John, D., and Melissa, S.M. (2016). Mobile application features sought after by patients of a regional grocery store chain pharmacy. Journal of the American Pharmacists Association. 56: 62-66. https://doi.org/10.1016/j.japh.2015.11.007

\section{Authors}

Orawit Thinnukool (corresponding author) received his $\mathrm{Ph} . \mathrm{D}$. Degree in Research Methodology. His background is in information technology, education technology and research operation. He is with the Department of Modern Management and Information Technology, College of Arts, Media and Technology, Chiang Mai University, Chiang Mai 50200, Thailand (orawit.t@cmu.ac.th)

Pattaraporn Khuwuthyakorn received her Ph.D. in Engineering from the Australian National University in 2012. Currently, she is a lecturer at the College of Arts, Media and Technology, Department of Modern Management and Information Technology, Chiang Mai University, Chiang Mai 50200, Thailand (pattaraporn.khuwuth@cmu.ac.th).

Purida Wientong received her Ph.D. in Pharmaceutical Care. Her area is in healthcare system and healthcare management. Currently she is a researcher and a lecturer of the Department of Pharmaceutical Care, Faculty of Pharmacy, Chiang Mai University, Chiang Mai 50200, Thailand (purida.v@cmu.ac.th). 
Paper-Non-Prescription Medicine Mobile Healthcare Application: Smartphone-Based Software Design...

Thammarat Panityakul he received his Ph.D. in Statistics. He is researcher and lecturer Department of Department of Mathematics and Statistics, Faculty of Science, Prince of Songkla University, Songkhla 90112, Thailand (thammarat.p@psu.ac.th). His area is statistics and data science.

Article submitted 09 May 2017. Published as resubmitted by the authors 28 July 2017. 